\title{
Differential gene expression of serine protease inhibitors in bovine ovarian follicle: possible involvement in follicular growth and atresia
}

\author{
Ken-Go Hayashi, Koichi Ushizawa, Misa Hosoe and Toru Takahashi*
}

\begin{abstract}
Background: SERPINs (serine protease inhibitors) regulate proteases involving fibrinolysis, coagulation, inflammation, cell mobility, cellular differentiation and apoptosis. This study aimed to investigate differentially expressed genes of members of the SERPIN superfamily between healthy and atretic follicles using a combination of microarray and quantitative real-time PCR (QPCR) analysis. In addition, we further determined mRNA and protein localization of identified SERPINs in estradiol (E2)-active and E2-inactive follicles by in situ hybridization and immunohistochemistry.

Methods: We performed microarray analysis of healthy $(10.7+/-0.7 \mathrm{~mm})$ and atretic $(7.8+/-0.2 \mathrm{~mm})$ follicles using a custom-made bovine oligonucleotide microarray to screen differentially expressed genes encoding SERPIN superfamily members between groups. The expression profiles of six identified SERPIN genes were further confirmed by QPCR analysis. In addition, mRNA and protein localization of four SERPINs was investigated in E2active and E2-inactive follicles using in situ hybridization and immunohistochemistry.
\end{abstract}

Results: We have identified 11 SERPIN genes expressed in healthy and atretic follicles by microarray analysis. QPCR analysis confirmed that mRNA expression of four SERPINs (SERPINA5, SERPINB6, SERPINE2 and SERPINF2) was greater in healthy than in atretic follicles, while two SERPINs (SERPINE1 and SERPING1) had greater expression in atretic than in healthy follicles. In situ hybridization showed that SERPINA5, SERPINB6 and SERPINF2 mRNA were localized in GCS of E2-active follicles and weakly expressed in GCs of E2-inactive follicles. SERPING1 mRNA was localized in both GCS and the theca layer (TL) of E2-inactive follicles and a weak hybridization signal was also detected in both GCs and TL of E2-active follicles. Immunohistochemistry showed that SERPINA5, SERPINB6 and SERPINF2 were detected in GCS of E2-active and E2-inactive follicles. SERPING1 protein was localized in both GCs and the TL of E2-active and E2-inactive follicles.

Conclusions: Our results demonstrate a characteristic expression of SERPIN superfamily member genes in bovine healthy and atretic follicles. The cell-type-and stage-specific expression of SERPINs may be associated with bovine follicular growth and atresia.

\section{Background}

The final growth of bovine antral follicles shows a wavelike pattern $[1,2]$. In each follicular wave, usually one dominant follicle (DF) is selected from a cohort of growing follicles and continues growth while other follicles undergo atresia [3]. The DF is characterized by expression of luteinizing hormone $(\mathrm{LH})$ receptor in

\footnotetext{
* Correspondence: tatoru@affrc.go.jp

Reproductive Biology Research Unit, Division of Animal Science, National Institute of Agrobiological Sciences, Tsukuba 305-8602, Japan
}

granulosa cells (GCs) and enhanced estradiol $\left(E_{2}\right)$ production [4]. Various intrafollicular molecules, including the insulin-like growth factor family and the transforming growth factor- $\beta$ family, play a crucial role in regulating DF selection and its further growth $[5,6]$. In addition, increasing evidence has revealed that numerous genes are regulated during bovine follicular development and ovulation through the use of global transcription profiling such as microarray analysis [7-15]. Recently, we investigated differences in global gene expression profiles between bovine healthy follicles

\section{() Biomed Central}


and atretic follicles using a bovine oligonucleotide microarray [15]. In that study 76 differentially expressed genes between the follicles were identified, demonstrating that gene expression in the follicles may be closely associated with their developmental status (healthy or atretic). Also in that study, we found several genes cording for serine protease inhibitors (SERPINs), being expressed in both healthy and atretic follicles.

SERPINs comprise a huge superfamily of protease inhibitors with similar structures that undergo conformational changes in the formation of stable complexes between inhibitor and target enzymes [16]. Most SERPINs inactivate serine proteases and some cystein proteases, and they play a functional role in diverse biological processes including fibrinolysis, coagulation, inflammation, cell mobility, cellular differentiation and apoptosis $[16,17]$. It has been reported that expression and secretion of three SERPINs, SERPINB2, SERPINE1 and SERPINE2 change in a stage-dependent manner during bovine follicular development and in the periovulatory period [18-21]. The mRNA expression of these SERPINs in preovulatory follicles was markedly up-regulated immediately after the beginning of the LH surge, then decreased to a nadir level near the time of ovulation [18,21]. During follicular development, SERPINE2 mRNA levels were higher in GCs of DF compared to small follicles [19] while the follicular fluid (FF) concentration of SERPINE2 was significantly higher in nonatretic than in atretic follicles [21]. An in vitro study demonstrated that cultured GCs from large follicles secreted more SERPINE2 than GCs from small and medium-sized follicles [20]. All of these three SERPINs are involved in the regulation of follicular extracellular matrix (ECM) remodeling to inhibit activity of plasminogen activators (PAs) and/or plasmin.

Even though a number of SERPINs with various functions are known, the presence of other SERPINs except for the above three SERPINs have not been examined in bovine follicles. We hypothesized that temporal and cell-specific regulation of SERPIN expression could contribute to follicular development in cattle. The aim of this study was to identify differentially expressed SERPIN genes between healthy and atretic follicles using a combination of microarray analysis and quantitative real-time PCR (QPCR) analysis. Moreover, mRNA and protein localization of several identified SERPINs was further investigated in $\mathrm{E}_{2}$-active and $\mathrm{E}_{2}$-inactive follicles using in situ hybridization and immunohistochemistry.

\section{Methods}

In the present study, the follicles used in experiment 1 and 2 were those previously used in our study [15]. The details of procedures for sample collection of experiment 1 and 2, RNA extraction, microarray analysis,
QPCR analysis, steroid hormone determinations and in situ hybridization have been described in our previous report [15]. All procedures for animal experiments were carried out in accordance with guidelines approved by the Animal Ethics Committee of the National Institute of Agrobiological Sciences for the use of animals.

\section{Experiment 1: identification of differentially expressed SERPIN genes by microarray analysis and QPCR analysis Sample collection and RNA extraction}

Paired ovaries were obtained from four pregnant Japanese Black cows (day 20-27 of pregnancy) in the institute ranch less than $10 \mathrm{~min}$ after slaughtering. These cows were pregnant and slaughtered for another study. Follicles that have the largest diameter and second-largest diameter within the paired ovaries were dissected, snap-frozen and stored at $-80^{\circ} \mathrm{C}$ until RNA extraction. We collected three largest and three second-largest follicles from four cows because two cows had both largest and second-largest follicles collected whereas one cow had only one largest follicle collected and another cow had only one second-largest follicle collected. As described in our previous study [15], we evaluated that the largest follicles were healthy while the second-largest follicles were atretic by differences in follicular gene expression profiles. The mean diameter of largest (healthy) and second-largest (atretic) follicles were 10.7 $\pm 0.7 \mathrm{~mm}$ and $7.8 \pm 0.2 \mathrm{~mm}$, respectively. Total RNA from the follicular wall (i.e., granulosa plus theca interna) was extracted from each follicle using ISOGEN (NipponGene, Tokyo, Japan) according to the manufacturer's instructions.

\section{Microarray analysis and quantitative real-time RT-PCR analysis}

We used a custom-made bovine oligonucleotide microarray fabricated by Agilent Technologies (Santa Clara, CA, USA). Sixty-mer nucleotides probes for customized microarray were synthesized on a glass slide. The annotated bovine oligonucleotide array represented 10263 sequences of which 4466 genes were known bovine genes including 14 SERPIN genes, 5697 unknown sequences that were possible candidates for novel bovine genes, and 100 internal references. We performed onecolor microarray using five follicles (three healthy follicles and two atretic follicles) as previously described [15]. After data normalization, 3308 genes were left to use for further analysis. The relative abundance of individual genes between follicles was calculated by dividing the normalized value of the genes between each follicle. Then, we picked up SERPIN genes that showed fluorescence intensities differing by at least a 2.0 -fold induction or a 0.5 -fold repression between healthy and atretic follicles and defined these genes as a potentially differential expression. Compliance with Minimum Information 
About a Microarray Experiment (MIAME) [22] was assured by depositing all the data in the Gene Expression Omnibus (GEO) repository [23]. The GEO accession numbers are as follows. Platform: GPL9136; Samples: GSM453634, GSM453635, GSM453636, GSM453637 and GSM453638; Series: GSE18145. We confirmed mRNA expression of six picked up SERPIN genes (SERPINA5, SERPINB6, SERPINE1, SERPINE2, SERPINF2 and SERPING1) using QPCR analysis to validate the results of microarray analysis. All six follicles were used in QPCR analysis. The procedures for QPCR were previously described [24]. The primer sequences for each gene are given in Table 1.

\section{Experiment 2: gene and protein localization of four SERPINs (SERPINA5, SERPINB6, SERPINF2 and SERPING1) in $E_{2}$-active and $E_{2}$-inactive follicles \\ Sample collection and follicular fluid steroid hormone determinations}

We obtained eleven large follicles ( $\geq 8 \mathrm{~mm}$ in diameter) from Japanease Black cows at a local slaughterhouse and aspirated $200 \mu \mathrm{l}$ of FF from the each follicle for hormone determinations. The follicles were dissected from the ovaries and fixed in $10 \%$ formalin, embedded in paraffin wax, and stored at $4^{\circ} \mathrm{C}$ until in situ hybridization and immunohistochemistry. The concentrations of $E_{2}$ and progesterone $\left(\mathrm{P}_{4}\right)$ in the FF samples were determined directly in duplicate using a time-resolved fluorescent immunoassay as described previously [25,26]. We classified follicles into two groups based on the relative levels of $\mathrm{E}_{2}$ and $\mathrm{P}_{4}$ in $\mathrm{FF}\left(\mathrm{E}_{2} / \mathrm{P}_{4} \geq 1: \mathrm{E}_{2}\right.$-active; $\mathrm{E}_{2} / \mathrm{P}_{4}<1$ : $\mathrm{E}_{2}$-inactive) [15].

In situ hybridization

Digoxigenin-labeled anti-sense and sense cRNA probes of each SERPINs were prepared as previously described $[27,28]$. For hybridization, follicles were sectioned into
7- $\mu$ m-thick sections. The procedure for in situ hybridization using an automated Ventana HX System Discovery with a RiboMapKit and a BlueMapKit (Roche Diagnostics, Basel, Switzerland) was previously described $[15,27,28]$.

\section{Immunohistochemistry}

Immunohistochemistory was performed using the automated Ventana HX System Discovery with a DabMapKit (Roche) described previously by our laboratory [29]. The 7 - $\mu$ m-thick follicular sections were incubated at room temperature for $4 \mathrm{~h}$ with rabbit polyclonal anti-SERPINA5 antibody (H00005104, Abnova, Taipei, Taiwan) diluted 1:10, rabbit polyclonal anti-SERPINB6 antibody (GTX114637, GeneTex Inc, Irvine, CA, USA) diluted $1: 100$, rabbit polyclonal anti-SERPINF2 antibody (H00005345, Abnova) diluted 1:20 or rabbit polyclonal anti-SERPING1 antibody (GTX105316, GeneTex) diluted 1:300 in Discovery Ab diluents (Roche). The sections were then incubated with anti-rabbit IgG-Biotin conjugate (B7389, Sigma, St. Louis, MO, USA) diluted 1:50 in Discovery Ab diluents (Roche) at room temperature for $1 \mathrm{~h}$. Immunoreactive signals were detected using streptavidin-HRP and diaminobenzidine (DabMapKit, Roche). Counter stain was performed by hematoxylin and bluing reagent (saturated lithium carbonate solution). Antibody specificity of these SERPIN antibodies in bovine follicles was confirmed by Western blot analyses on bovine follicular lysates (GCs and theca interna).

\section{Statistical analysis}

In experiment 1, the expression ratio of each gene to GAPDH mRNA was calculated to adjust for variations in the QPCR reaction. QPCR data in experiment 1 was analyzed by a Mann-Whitney's U test. Results are presented as the mean \pm SEM. Statistical significance was considered at $P<0.05$.

Table 1 Details of the primers used for quantitative real-time RT-PCR analysis

\begin{tabular}{|c|c|c|c|c|}
\hline Gene name & GeneBank accession number & Primer & Sequences & Position \\
\hline \multirow[t]{2}{*}{ SERPINA5 } & NM_176646 & Forward & 5'-TGGAAAATGGCCTGAAGGAA-3' & 889-908 \\
\hline & & Reverse & 5'-ATAAAGCTCAAGCCGCCTCTT-3' & $962-942$ \\
\hline \multirow[t]{2}{*}{ SERPINB6 } & NM_174789 & Forward & 5'-AGCACCCAGATTCTGGTTCTTC-3' & $725-746$ \\
\hline & & Reverse & 5'-GTGTTCAAGTCCGTGCTTTCAC-3' & 810-789 \\
\hline \multirow[t]{2}{*}{ SERPINE1 } & NM_174137 & Forward & 5'-CAGGCGGACTTCTCCAGTITT-3' & 1097-1117 \\
\hline & & Reverse & 5'-ACCTCAATCTTCACCTTCTGCAG-3' & 1173-1151 \\
\hline \multirow[t]{2}{*}{ SERPINE2 } & NM_174669 & Forward & 5'-CGTAGCACAGACAGATTTGAAGGA-3' & 1068-1091 \\
\hline & & Reverse & 5'- GCAAAATTCGCCTITGATGG-3' & 1148-1129 \\
\hline \multirow[t]{2}{*}{ SERPINF2 } & NM_174670 & Forward & 5'-CCTGGAACAATCAGAACAGCTCT-3' & $579-601$ \\
\hline & & Reverse & 5'-TAATGTTCGCCAGGTCTTCCC-3' & $658-638$ \\
\hline \multirow[t]{2}{*}{ SERPING1 } & NM_174821 & Forward & 5'-GAGATGACCAAGTTCCATCCCA-3' & 1081-1102 \\
\hline & & Reverse & 5'-GTAATCCAGCATGTCCTGACTGC-3' & 1158-1136 \\
\hline \multirow[t]{2}{*}{ GAPDH } & U85042 & Forward & 5'- ACCCAGAAGACTGTGGATGG-3' & $444-463$ \\
\hline & & Reverse & 5'-CAACAGACACGTTGGGAGTG-3' & $621-602$ \\
\hline
\end{tabular}




\section{Results}

\section{Experiment 1}

Microarray analysis and quantitative real-time $P C R$ analysis Among 14 genes coding for the SERPIN superfamily represented on a bovine oligonucleotide array, 11 SERPIN genes were identified after data normalization: SERPINA1, SERPINA5, SERPINB1, SERPINB6, SERPINB8, SERPINE1, SERPINE2, SERPINF1, SERPINF2, SERPING1 and SERPINH1. Of these 11 SERPIN genes, SERPINA5, SERPINB6, SERPINE2 and SERPINF2 were consistently up-regulated at least 2.0-fold, while SERPINE1 and SERPING1 were consistently down-regulated at least 0.5 -fold in all healthy follicles compared with all atretic follicles. We compared the expression levels of these six SERPINs between healthy and atretic follicles by QPCR. Figure 1 shows the results of QPCR analysis. Consistent with the microarray analysis, SERPINA5, SERPINB6, SERPINE2 and SERPINF2 mRNA expression was greater in healthy than in atretic follicles $(P<0.05)$. On the other hand, SERPINE1 and SERPING1 mRNA expression was greater in atretic than in healthy follicles $(P<0.05)$.

\section{Experiment 2}

Among the six SERPINs analyzed by QPCR in experiment 1 , we investigated the mRNA and protein localization of four (SERPINA5, SERPINB6, SERPINF2 and SERPING1) in $E_{2}$-active and $E_{2}$-inactive follicles. These SERPINs have not been previously described in bovine ovarian follicles.

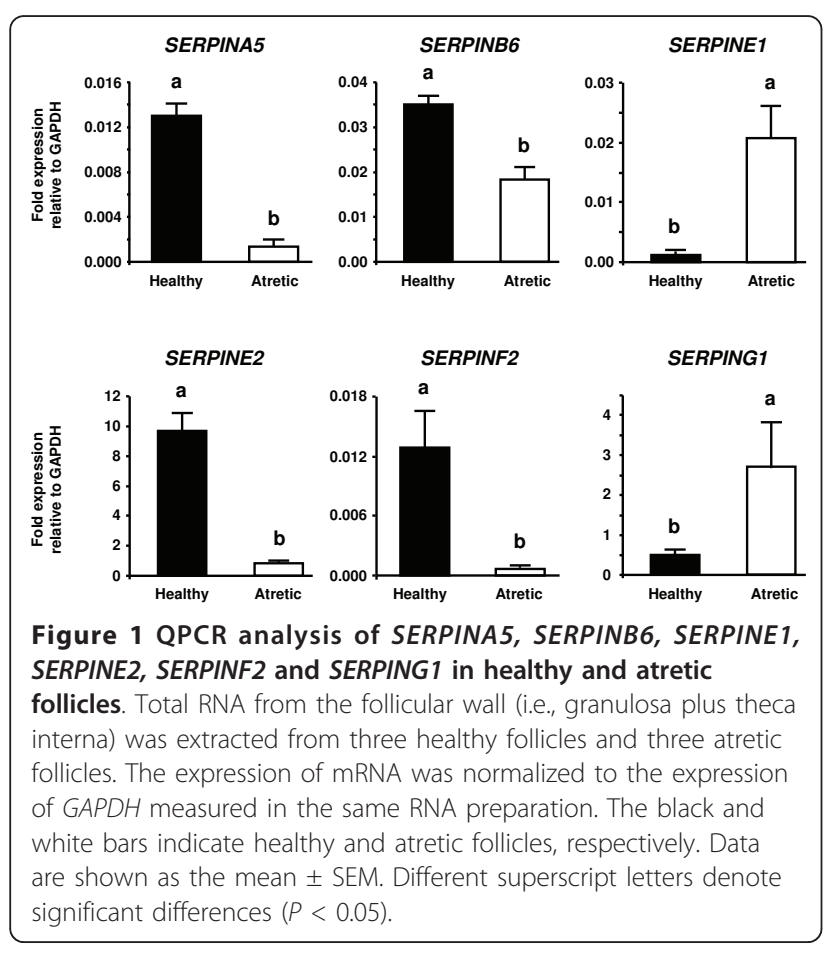

In situ hybridization of four SERPIN genes in $\mathrm{E}_{2}$-active and $E_{2}$-inactive follicles

As shown in Figure 2, mRNA expressions of SERPINA5, SERPINB6 and SERPINF2 were detected in GCs of $E_{2}$ active follicles and a weak hybridization signal was also detected in GCs of $\mathrm{E}_{2}$-inactive follicles (Figure 2A, C, E, G, I and 2K). SERPING1 mRNA was localized in both GCs and the TL of $E_{2}$-inactive follicles and a weak hybridization signal was also detected in both GCs and the TL of $\mathrm{E}_{2}$-active follicles (Figure $2 \mathrm{M}$ and $2 \mathrm{O}$ ). No significant signals were detected with any sense probes (Figure 2B, D, F, H, J, L, N and 2P).

\section{Immunohistochemistry of four SERPIN proteins in $E_{2^{-}}$ active and $E_{2}$-inactive follicles}

SERPINA5, SERPINB6 and SERPINF2 were detected in GCs of $E_{2}$-active and $E_{2}$-inactive follicles (Figure $3 \mathrm{~A}, \mathrm{~B}$, $\mathrm{C}, \mathrm{D}, \mathrm{E}$ and $3 \mathrm{~F}$ ). SERPING1 protein was localized in both $\mathrm{GCs}$ and the TL of $E_{2}$-active and $E_{2}$-inactive follicles (Figure 3G and $3 \mathrm{H}$ ).

\section{Discussion}

This study focused on the mRNA expression of SERPINs during bovine follicular development. Microarray and QPCR analyses revealed that a total of 11 SERPINs are expressed in both healthy and atretic follicles. Of these, nine were identified for the first time in bovine follicle while six were differentially expressed between healthy and atretic follicles. We also demonstrate that four of the identified SERPIN genes and proteins showed stage-specific localization in $E_{2}$-active and $E_{2}$ inactive follicles.

In the present study, the mRNA expression of four out of six SERPINs differentially expressed between healthy and atretic follicles was detected for the first time in bovine follicles. These SERPINs are mainly involved in regulation of fibrinolytic, coagulation and protein C pathways. SERPINA5 showed higher mRNA expression in healthy than in atretic follicles. This SERPIN is also called protein $C$ inhibitor and regulates the coagulation cascade by following three pathways; 1 ) inhibition of down-regulation of the coagulation pathway to inhibit activated protein $\mathrm{C}$ (APC), 2) anticoagulant function in the presence of heparin by inhibiting proteolytic cleavage of fibrinogen by thrombin, 3) procoagulation function in the presence of thrombomodulin by inhibiting activation of protein $C$ by thrombin [30]. In bovine follicles, GCs express prothorombin (thrombin precursor) and thrombin receptor (PAR-1) mRNA and FF contains prothorombin, heparin sulfate and thrombin-generating proteins (Factor V, VII and X) [31,32], suggesting that the coagulation cascade is locally activated in bovine follicles. Our present result reveals that mRNA and protein of SERPINA5 was localized only in 


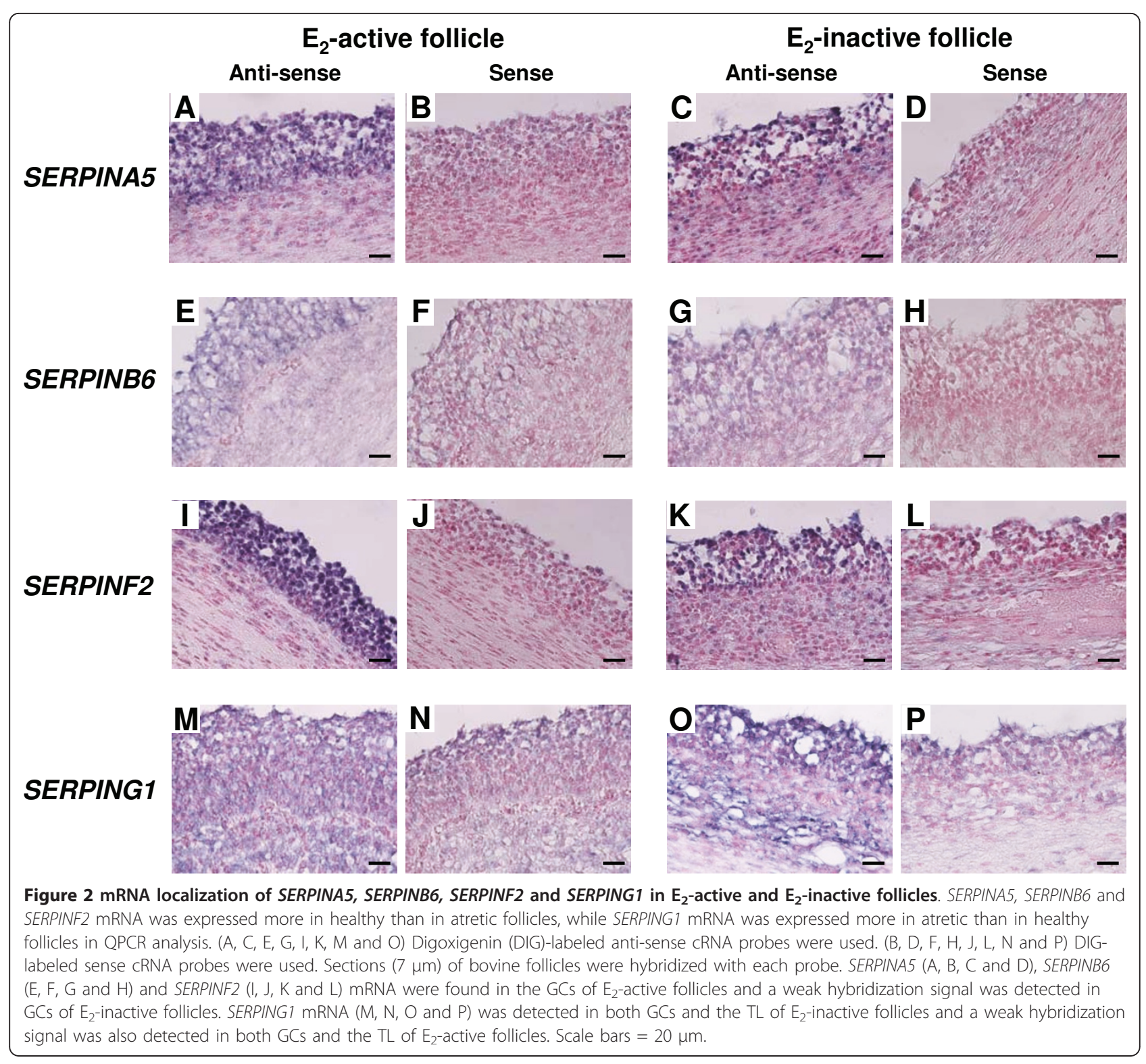

the GCs. Thus, it is plausible that GCs are the main site of action of protein $\mathrm{C}$ and thrombin in bovine follicles. In addition, APC has direct anti-inflammatory and antiapoptotic properties by cleaving PAR-1 [30]. SERPINA5 in healthy follicles may be involved in the regulation of not only the coagulation cascade but also the antiinflammation and anti-apoptotic functions of APC.

SERPING1 (C1 inhibitor) regulates complement pathway activation and blocks the activity of plasma kallikrein and the activated form of factor XII in blood [33]. These two proteins participate in the production of bradykinin, which promotes inflammation by increasing vascular permeability [34]. The presence of the bradykinin-producing system within follicles has been suggested in porcine since plasma kallikrein and its physiological substrate HMW-kininogen coexist in the FF [35]. We found that SERPING1 mRNA was more highly expressed in atretic than in healthy follicles and both mRNA and protein was detected in the GCs and the TL of $\mathrm{E}_{2}$-inactive follicles. High expression of SERPING1 mRNA in atretic follicles may regulate vascular permeability and suppress inflammation promoted by bradykinin. To support our results, it has been speculated that bradykinin is involved in the selection and atresia of ovarian follicles because the porcine study demonstrated that the concentration of bradykinin in FF of small follicles was higher than in the FF of medium and large follicles [35].

Fibrinolytic cascades, including the PA-plasmin system, play a crucial role in the degradation and remodeling of 


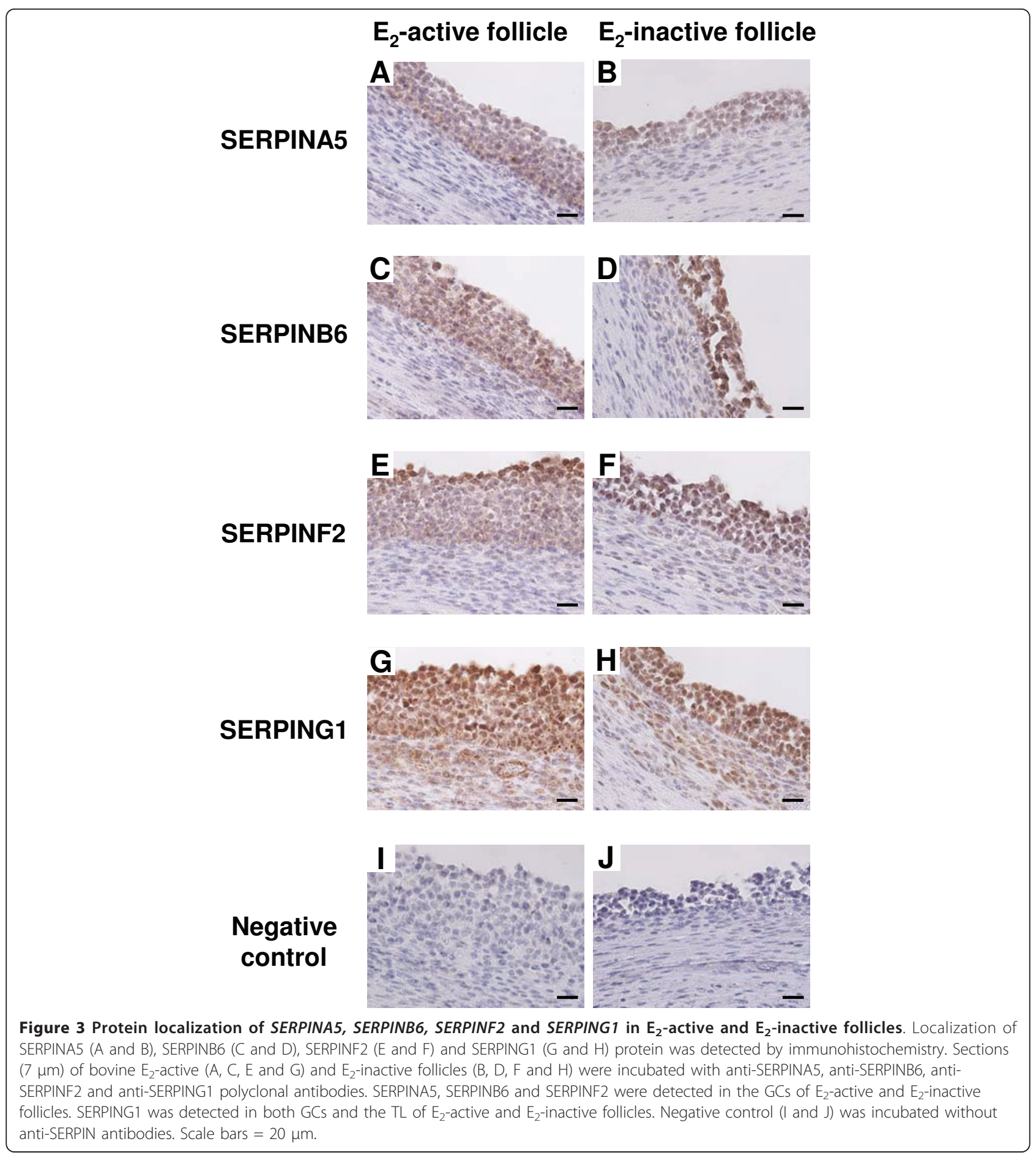

follicular basal lamina and ECM associated with follicular development, ovulation and atresia [36]. In the present study, both SERPINE2 and SERPINF2 mRNA were found to be more greatly expressed in healthy than in atretic follicles. SERPINE2 is a potent inhibitor of thrombin, plasmin, both urokinase (uPA) and tissue-type PA (tPA) $[37,38]$. mRNA and protein expression of SERPINE2 were detected in bovine GCs [19]. In accordance with our results, the FF protein level and mRNA expression of SERPINE2 in GCs were higher in non-atretic than in atretic follicles [21]. SERPINF2 is a known primary physiological inhibitor of plasmin $[17,39]$. Our results demonstrated for the first time that SERPINF2 mRNA is expressed in ovarian follicles and both the mRNA and the protein are 
localized in the GCs of healthy and atretic follicles. Only GCs express both SERPINE2 and SERPINF2, suggesting that GCs may play an important role in the regulation of the PA-plasmin cascade. Atretic follicles had higher FF plasmin activity than non-atretic follicles while there was no difference in mRNA expression levels of uPA [21]. We previously demonstrated that mRNA expression of uPA receptor was higher in atretic than in healthy follicles [15]. Therefore, we speculate that the follicular PA-plasmin system may mainly be regulated by changes in the balance of expression of their inhibitors and receptors.

Although SERPINE1 as well as SERPINE2 acts as a primary inhibitor of both uPA and tPA [40], its mRNA expression was higher in atretic than in healthy follicles in contrast to SERPINE2. A previous study showed that there was no difference in mRNA expression levels of SERPINE1 between non-atretic and atretic bovine follicles [21]. However, SERPINE1 mRNA expression may decrease in the process of bovine follicular development since it was down-regulated in large follicles $(10 \mathrm{~mm}$ in diameter) compared with medium-sized follicles $(8 \mathrm{~mm}$ in diameter) [14]. SERPINE1 is an acute phase protein and its production dramatically increases in response to cytokines such as interleukin-1 $\beta$ (IL-1 $\beta$ ) and tumor necrosis factor $\alpha$ (TNF $\alpha)[41,42]$. An in vitro study of cultured rat GCs revealed that both IL-1 $\beta$ and TNF $\alpha$ suppressed the gonadotropin-induced enhancement of PAs activity, which was accompanied by an increase in plasminogen activator inhibitor activity $[43,44]$. Expression of TNF $\alpha$ mRNA was greater in bovine GCs of subordinate follicles compared with DF [7]. Thus, greater mRNA expression of SERPINE1 in atretic follicles may be stimulated by enhanced ILs and TNF $\alpha$ production during follicular atresia.

Healthy follicles also showed greater expression of SERPINB6 mRNA than atretic follicles. In our present study, in situ hybridization and immunohistochemistry revealed that mRNA and protein localization of SERPINB6 was restricted only to the GCs of bovine follicles. It has been demonstrated that Spi/SERPINB6, which is the mouse ortholog of SERPINB6, and two Spi3/SERPINB6 paralogs, NK13/SERPINB6b and Spi3C/SERPINB6c, were expressed in a mouse follicular somatic cells and/or oocytes [45]. A primary target protease of SERPINB6 is cathepsin G [46], whereas its gene expression is likely to be restricted to the myeloid lineage [47] while the expression in ovarian follicular cells is unknown. SERPINB6 modulates proteolytic activities of a variety of proteases including plasmin, thrombin, tissue kallikrein and trypsin and $\beta$-tryptase [48,49]. mRNA and protein of tissue kallikrein, thrombin and plasmin are localized in GCs of bovine antral follicles and are thought to contribute to regulation of follicular angiogenesis, coagulation or tissue remodeling $[32,50]$.
SERPINB6 is apparently restricted to the cytoplasm of cells and cannot be released via the conventional secretory pathway [51]. Thus, we speculate that SERPINB6 may participate in follicular development to inhibit intracellular proteases in GCs.

Furthermore, we identified for the first time five SERPIN genes (SERPINA1, SERPINB1, SERPINB8, SERPINF1 and SERPINH1) that are expressed in bovine follicles by microarray analysis. The primary functions of these SERPINs are inhibition of neutrophil elastase (SERPINA1 and SERPINB1) [52,53], inhibition of furin (SERPINB8) [54] and antiangiogenic molecule (SERPINF1) [55]. SERPINH1 is known as heat shock protein 47 and is involved in molecular maturation of collagens to act as a collagen-specific molecular chaperone which does not have a protease inhibitory function [56]. This SERPIN may modulate biosynthesis of collagens in follicles regardless of their health status because the mRNA of collagen types I and IV are detected in GCs and in the basement membrane of bovine follicles [57]. Our results imply that numerous SERPINs may constantly participate in regulation of follicular functions.

\section{Conclusions}

We have identified 11 SERPIN genes that are expressed in bovine follicles by microarray analysis. Of these, six are differentially expressed between healthy and atretic follicles. In addition, we have demonstrated for the first time that mRNA and protein of SERPINA5, SERPINB6 and SERPINF2 showed characteristic localization in the GCs of follicles, whereas mRNA and protein of SERPING1 was localized in both GCs and TL of $E_{2}$-active and $\mathrm{E}_{2}$-inactive follicles. Stage-specific expression of SERPINs may participate in the growth and atresia of bovine follicles as important mediators of diverse local mechanisms such as coagulation, protein $\mathrm{C}$ and fibrinolytic pathways.

\section{Acknowledgements}

This study was supported by a grant-in-aid from the Ministry of Agriculture, Forestry and Fisheries Japan (17-1770). KGH was supported by the Japan Society for the Promotion of Science Research Fellowships for Young Scientists (0702379). This manuscript was reviewed by a professional service (MS106304, SciRevision, Kagawa, Japan) prior to submission.

\section{Authors' contributions}

$\mathrm{KGH}$ participated in the design of the study, collected the materials, carried out all experiments and drafted the manuscript. KU collected the materials, carried out the microarray experiments and analysis, and helped to carry out QPCR and in situ hybridization. MH was responsible for all animal care, collected the materials and carried out the microarray experiments. TT supervised the study, collected the materials and helped to draft the manuscript. All authors read and approved the final manuscript.

\section{Competing interests}

The authors declare that they have no competing interests.

Received: 2 November 2010 Accepted: 27 May 2011

Published: 27 May 2011 


\section{References}

1. Sirois J, Fortune JE: Ovarian follicular dynamics during the estrous cycle in heifers monitored by real-time ultrasonography. Biol Reprod 1988 39:308-317.

2. Ginther OJ, Knopf L, Kastelic JP: Temporal associations among ovarian events in cattle during oestrous cycles with two and three follicular waves. J Reprod Fertil 1989, 87:223-230.

3. Sunderland SJ, Crowe MA, Boland MP, Roche JF, Ireland JJ: Selection, dominance and atresia of follicles during the oestrous cycle of heifers. J Reprod Fertil 1994, 101:547-555.

4. Ginther OJ, Wiltbank MC, Fricke PM, Gibbons JR, Kot K: Selection of the dominant follicle in cattle. Biol Reprod 1996, 55:1187-1194.

5. Fortune JE, Rivera GM, Yang MY: Follicular development: the role of the follicular microenvironment in selection of the dominant follicle. Anim Reprod Sci 2004, 82-83:109-126.

6. Knight PG, Glister C: TGF-beta superfamily members and ovarian follicle development. Reproduction 2006, 132:191-206

7. Evans AC, Ireland JL, Winn ME, Lonergan P, Smith GW, Coussens PM, Ireland JJ: Identification of genes involved in apoptosis and dominant follicle development during follicular waves in cattle. Biol Reprod 2004, 70:1475-1484.

8. Ndiaye K, Fayad T, Silversides DW, Sirois J, Lussier JG: Identification of downregulated messenger RNAs in bovine granulosa cells of dominant follicles following stimulation with human chorionic gonadotropin. Biol Reprod 2005, 73:324-333.

9. Mihm M, Baker PJ, Ireland JL, Smith GW, Coussens PM, Evans AC, Ireland JJ: Molecular evidence that growth of dominant follicles involves a reduction in follicle-stimulating hormone dependence and an increase in luteinizing hormone dependence in cattle. Biol Reprod 2006, 74:1051-1059.

10. Zielak AE, Forde N, Park SD, Doohan F, Coussens PM, Smith GW, Ireland رل Lonergan $\mathrm{P}$, Evans AC: Identification of novel genes associated with dominant follicle development in cattle. Reprod Fertil Dev 2007, 19:967-975.

11. Zielak AE, Canty MJ, Forde N, Coussens PM, Smith GW, Lonergan P, Ireland JJ, Evans AC: Differential expression of genes for transcription factors in theca and granulosa cells following selection of a dominant follicle in cattle. Mol Reprod Dev 2008, 75:904-914.

12. Skinner MK, Schmidt M, Savenkova MI, Sadler-Riggleman I, Nilsson EE: Regulation of granulosa and theca cell transcriptomes during ovarian antral follicle development. Mol Reprod Dev 2008, 75:1457-1472.

13. Mihm M, Baker PJ, Fleming LM, Monteiro AM, O'Shaughnessy PJ: Differentiation of the bovine dominant follicle from the cohort upregulates mRNA expression for new tissue development genes. Reproduction 2008, 135:253-265.

14. Liu Z, Youngquist RS, Garverick HA, Antoniou E: Molecular mechanisms regulating bovine ovarian follicular selection. Mol Reprod Dev 2009, 76:351-366.

15. Hayashi KG, Ushizawa K, Hosoe M, Takahashi T: Differential genome-wide gene expression profiling of bovine largest and second-largest follicles: identification of genes associated with growth of dominant follicles. Reprod Biol Endocrinol 2010, 8:11.

16. Law RH, Zhang Q, McGowan S, Buckle AM, Silverman GA, Wong W, Rosado CJ, Langendorf CG, Pike RN, Bird PI, Whisstock JC: An overview of the serpin superfamily. Genome Biol 2006, 7:216.

17. Rau JC, Beaulieu LM, Huntington JA, Church FC: Serpins in thrombosis, hemostasis and fibrinolysis. J Thromb Haemost 2007, 5(Suppl 1):102-115.

18. Dow MP, Bakke LJ, Cassar CA, Peters MW, Pursley JR, Smith GW: Gonadotrophin surge-induced upregulation of mRNA for plasminogen activator inhibitors 1 and 2 within bovine periovulatory follicular and luteal tissue. Reproduction 2002, 123:711-719.

19. Bedard J, Brule S, Price CA, Silversides DW, Lussier JG: Serine protease inhibitor-E2 (SERPINE2) is differentially expressed in granulosa cells of dominant follicle in cattle. Mol Reprod Dev 2003, 64:152-165.

20. Cao M, Sahmi M, Lussier JG, Price CA: Plasminogen activator and serine protease inhibitor-E2 (protease nexin-1) expression by bovine granulosa cells in vitro. Biol Reprod 2004, 71:887-893.

21. Cao M, Buratini J Jr, Lussier JG, Carriere PD, Price CA: Expression of protease nexin-1 and plasminogen activators during follicular growth and the periovulatory period in cattle. Reproduction 2006, 131:125-137.

22. MIAME:[http://www.mged.org/Workgroups/MIAME/miame.html].
23. GEO:[http://www.ncbi.nlm.nih.gov/projects/geo/]

24. Ushizawa K, Takahashi T, Hosoe M, Ishiwata H, Kaneyama K, Kizaki K, Hashizume K: Global gene expression analysis and regulation of the principal genes expressed in bovine placenta in relation to the transcription factor AP-2 family. Reprod Biol Endocrinol 2007, 5:17.

25. Takahashi T, Hamanaka S, Ikeda S, Kobayashi J, Hashizume K: A direct timeresolved fluorescent immunoassay (TR-FIA) for measuring plasma progesterone concentration in sika doe (Cervus nippon centralis). J Reprod Dev 2001, 47:119-123.

26. Takahashi T, Hamanaka S, Imai K, Hashizume K: A direct time-resolved fluoroimmunoassay (TR-FIA) for measuring plasma estradiol-17beta concentrations in cattle. J Vet Med Sci 2004, 66:225-229.

27. Ushizawa K, Kaneyama K, Takahashi T, Tokunaga T, Tsunoda Y, Hashizume K Cloning and expression of a new member of prolactin-related protein in bovine placenta: bovine prolactin-related protein-VII. Biochem Biophys Res Commun 2005, 326:435-441.

28. Ushizawa K, Takahashi T, Kaneyama K, Hosoe M, Hashizume K: Cloning of the bovine antiapoptotic regulator, $\mathrm{BCL} 2$-related protein $\mathrm{A} 1$, and its expression in trophoblastic binucleate cells of bovine placenta. Biol Reprod 2006, 74:344-351.

29. Ushizawa K, Takahashi T, Hosoe M, Kizaki K, Hashizume K: Characterization and expression analysis of SOLD1, a novel member of the retrotransposon-derived Ly-6 superfamily, in bovine placental villi. PLOS One 2009, 4:e5814

30. Dahlback B, Villoutreix BO: The anticoagulant protein C pathway. FEBS Lett 2005, 579:3310-3316

31. Bushmeyer SM, Bellin ME, Brantmeier SA, Boehm SK, Kubajak CL, Ax RL: Relationships between bovine follicular fluid glycosaminoglycans and steroids. Endocrinology 1985, 117:879-885.

32. Roach LE, Petrik JJ, Plante L, LaMarre J, Gentry PA: Thrombin generation and presence of thrombin receptor in ovarian follicles. Biol Reprod 2002, 66:1350-1358.

33. Davis $A E$, Mejia $P$, Lu F: Biological activities of $C 1$ inhibitor. Mol Immunol 2008, 45:4057-4063.

34. Moreau ME, Garbacki N, Molinaro G, Brown NJ, Marceau F, Adam A: The kallikrein-kinin system: current and future pharmacological targets. $J$ Pharmacol Sci 2005, 99:6-38.

35. Kihara T, Kimura A, Moriyama A, Ohkubo I, Takahashi T: Identification of components of the intrafollicular bradykinin-producing system in the porcine ovary. Biol Reprod 2000, 62:1160-1167.

36. Ny T, Wahlberg $P$, Brandstrom IJ: Matrix remodeling in the ovary: regulation and functional role of the plasminogen activator and matrix metalloproteinase systems. Mol Cell Endocrinol 2002, 187:29-38.

37. Baker JB, Low DA, Simmer RL, Cunningham DD: Protease-nexin: a cellular component that links thrombin and plasminogen activator and mediates their binding to cells. Cell 1980, 21:37-45.

38. Scott RW, Bergman BL, Bajpai A, Hersh RT, Rodriguez H, Jones BN, Barreda C, Watts S, Baker JB: Protease nexin. Properties and a modified purification procedure. J Biol Chem 1985, 260:7029-7034

39. Coughlin PB: Antiplasmin: the forgotten serpin? Febs J 2005 272:4852-4857.

40. Cesarman-Maus G, Hajiar KA: Molecular mechanisms of fibrinolysis. $\mathrm{Br}$ Haematol 2005, 129:307-321.

41. Schleef RR, Bevilacqua MP, Sawdey M, Gimbrone MA Jr, Loskutoff DJ: Cytokine activation of vascular endothelium. Effects on tissue-type plasminogen activator and type 1 plasminogen activator inhibitor. $J$ Biol Chem 1988, 263:5797-5803.

42. Dong J, Fujii S, Goto D, Furumoto T, Kaneko T, Zaman TA, Nakai Y, Mishima T, Imagawa S, Kitabatake A: Increased expression of plasminogen activator inhibitor- 1 by mediators of the acute phase response: a potential progenitor of vasculopathy in hypertensives. Hypertens Res 2003, 26:723-729

43. Karakji EG, Tsang BK: Regulation of rat granulosa cell plasminogen activator system: influence of interleukin-1 beta and ovarian follicula development. Biol Reprod 1995, 53:1302-1310.

44. Karakji EG, Tsang BK: Tumor necrosis factor alpha inhibits rat granulosa cell plasminogen activator activity in vitro during follicular development. Biol Reprod 1995, 52:745-752

45. Charron Y, Madani R, Nef S, Combepine C, Govin J, Khochbin S, Vassalli JD: Expression of serpinb6 serpins in germ and somatic cells of mouse gonads. Mol Reprod Dev 2006, 73:9-19. 
46. Scott FL, Hirst CE, Sun J, Bird CH, Bottomley SP, Bird PI: The intracellular serpin proteinase inhibitor 6 is expressed in monocytes and granulocytes and is a potent inhibitor of the azurophilic granule protease, cathepsin G. Blood 1999, 93:2089-2097.

47. Grisolano JL, Sclar GM, Ley TJ: Early myeloid cell-specific expression of the human cathepsin G gene in transgenic mice. Proc Natl Acad Sci USA 1994, 91:8989-8993.

48. Sun J, Coughlin P, Salem HH, Bird P: Production and characterization of recombinant human proteinase inhibitor 6 expressed in Pichia pastoris. Biochim Biophys Acta 1995, 1252:28-34.

49. Scott FL, Sun J, Whisstock JC, Kato K, Bird PI: SerpinB6 is an inhibitor of kallikrein-8 in keratinocytes. J Biochem 2007, 142:435-442.

50. Plendl J, Snyman C, Bhoola KD: Expression of the tissue kallikrein-kinin cascade in granulosa cells of the ovary. Biol Chem 2002, 383:1917-1924.

51. Scott FL, Coughlin PB, Bird C, Cerruti L, Hayman JA, Bird P: Proteinase inhibitor 6 cannot be secreted, which suggests it is a new type of cellular serpin. J Biol Chem 1996, 271:1605-1612.

52. Beatty K, Bieth J, Travis J: Kinetics of association of serine proteinases with native and oxidized alpha-1-proteinase inhibitor and alpha-1antichymotrypsin. J Biol Chem 1980, 255:3931-3934.

53. Kordula T, Dubin A, Schooltink H, Koj A, Heinrich PC, Rose-John S: Molecular cloning and expression of an intracellular serpin: an elastase inhibitor from horse leucocytes. Biochem J 1993, 293(Pt 1):187-193.

54. Dahlen JR, Jean F, Thomas G, Foster DC, Kisiel W: Inhibition of soluble recombinant furin by human proteinase inhibitor 8 . J Biol Chem 1998 273:1851-1854

55. Dawson DW, Volpert OV, Gillis P, Crawford SE, XU H, Benedict W, Bouck NP: Pigment epithelium-derived factor: a potent inhibitor of angiogenesis. Science 1999, 285:245-248.

56. Nagata K, Hosokawa N: Regulation and function of collagen-specific molecular chaperone, HSP47. Cell Struct Funct 1996, 21:425-430.

57. Zhao Y, Luck MR: Gene expression and protein distribution of collagen fibronectin and laminin in bovine follicles and corpora lutea. J Reprod Fertil 1995, 104:115-123.

doi:10.1186/1477-7827-9-72

Cite this article as: Hayashi et al:. Differential gene expression of serine protease inhibitors in bovine ovarian follicle: possible involvement in follicular growth and atresia. Reproductive Biology and Endocrinology 2011 9:72.

\section{Submit your next manuscript to BioMed Central and take full advantage of:}

- Convenient online submission

- Thorough peer review

- No space constraints or color figure charges

- Immediate publication on acceptance

- Inclusion in PubMed, CAS, Scopus and Google Scholar

- Research which is freely available for redistribution

Submit your manuscript at www.biomedcentral.com/submit 